\title{
VIBRATIONS OF CAM MECHANISMS
}


Philips Technical Library

\title{
VIBRATIONS OF CAM MECHANISMS \\ Consequences of their design
}

\author{
M. P. KOSTER
}

Macmillan Education 
ISBN 978-1-349-02457-5 ISBN 978-1-349-02455-1 (eBook)

DOI 10.1007/978-1-349-02455-1

English edition (C) N. V. Philips' Gloeilampenfabrieken, Eindhoven, 1974

Softcover reprint of the hardcover 1st edition 1974 978-0-333-17732-7

All rights reserved. No part of this publication may be reproduced or transmitted in any form, or by any means, without permission.

SBN 333177320

First published 1974 by

THE MACMILLAN PRESS LTD

London and Basingstoke

Associated companies in New York Melbourne

Dublin Johannesburg and Madras

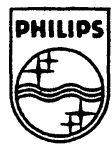

PHILIPS

Trademarks of N. V. Philips' Gloeilampenfabrieken 


\section{PREFACE}

The book is intended both for those who are interested in the theoretical backgrounds of machine dynamics and for the engineering designer.

The book, initiated by the author's design work relating to production machines, contains a theoretical analysis and rules of design which are applicable in the field of the design of high-accuracy, fast-running machines, without recourse to computer-aided programs.

These rules are formulated in order to design machines which fulfil requirements concerning positional accuracy and dynamic load; they can be used by the designer without specialised knowledge of the theory of dynamics.

The dynamic behaviour of machines can be predicted if the mechanism is represented by a mathematical model. In this book, cam mechanisms and their driving components, i.e. the camshaft, the reduction gear, and the driving asynchronous motor are investigated, but the methods and results are of wider applicability.

Transient vibrations characterise the dynamic behaviour of cam mechanisms. In present-day machines the main cause of follower vibration is often inadequate shaft rigidity. Several mathematical models have been developed and tested. Detailed analysis of machine vibrations can be obtained by means of a digital simulation program based on a model with four degrees of freedom. Follower and shaft vibrations and the effects of nonlinear phenomena, i.e. backlash, squeeze, and impact are simulated. Based on a model with one degree of freedom rules of design concerning the cam follower linkage and the driving components are drawn up. A number of examples are given.

Eindhoven,

M. P. Koster

May 1974 


\section{ACKNOWLEDGMENT}

This book first appeared in 1973 as a thesis. Sincere thanks are due to all who have contributed to these investigations, especially to prof. dr ir J. D. Janssen and prof. ir W. van der Hoek for their support during the preparation of the thesis, to Mr. J. A. M. Spapens for his enthusiastic cooperation, to $\mathrm{Mr}$. J. A. Versantvoort for his advice relating to the application of the software package COSILA, and to Mr. H. G. E. Wallace for his critical remarks and conscientious revision of the text.

Eindhoven,

M. P. Koster

May 1974 


\section{CONTENTS}

\section{SYMBOLS}

1. INTRODUCTION . . . . . . . . . . . . . . . . . . 1

1.1. Mechanisms . . . . . . . . . . . . . . . . . . . 1

1.2. Why the interest in the dynamics of cam mechanisms . . . . 2

1.3. State of the art . . . . . . . . . . . . . . . . . . . . . . 3

1.4. The aim of the present investigation . . . . . . . . . . . . . 9

1.5. Survey of the present investigation . . . . . . . . . . . . . 10

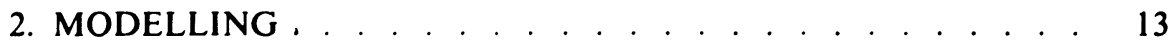

2.1. Introduction . . . . . . . . . . . . . . . . . . . . . . . 13

2.2. Degrees of freedom . . . . . . . . . . . . . . . . . . . . 13

2.2.1. Continuous systems . . . . . . . . . . . . . . . . 13

2.2.2. Discrete systems . . . . . . . . . . . . . . . . . . 15

2.2.2.1. Static and dynamic coupling . . . . . . . . . 15

2.2.2.2. Static coupling only . . . . . . . . . . . . . 25

2.3. Dynamic model . . . . . . . . . . . . . . . . . . . . . 29

2.3.1. Transmission ratio . . . . . . . . . . . . . . . . . 29

2.3.2. Addition of motions . . . . . . . . . . . . . . . . 32

2.3.3. Dynamic models of machine components . . . . . . . 33

2.3.4. Example . . . . . . . . . . . . . . . . . . . . . 33

2.4. Reduction . . . . . . . . . . . . . . . 35

2.4.1. Reduction of linear dimensions . . . . . . . . . . . 35

2.4.2. Reduction of mass . . . . . . . . . . . . . . . . . 35

2.4.3. Reduction of stiffness . . . . . . . . . . . . . . . . . 36

2.4.4. Reduction of a linear, viscous damper . . . . . . . . 37

2.4.5. Reduction of viscosity . . . . . . . . . . . . . . . . 37

2.4.6. Example . . . . . . . . . . . . . . . . . . . . . 38

2.5. Details of the dynamic model . . . . . . . . . . . . . . . 38

2.5.1. Variable transmission ratio $\tan x$. . . . . . . . . . . 40

2.5.2. Variable magnitudes of $m_{\beta}{ }^{\prime}$ and $c_{\beta}{ }^{\prime}$. . . . . . . . . . 40

3. SINGLE-DEGREE-OF-FREEDOM MODEL WITH CONSTANT FICTITIOUS ANGULAR VELOCITY ........... . 42

3.1. Introduction . . . . . . . . . . . . . . . . . . . . . . . 42

3.2. Assumptions . . . . . . . . . . . . . . . . . . . . . . . 42

3.2.1. Constant fictitious angular velocity . . . . . . . . . . 42

3.2.1.1. Infinitely rigid camshaft . . . . . . . . . . . 42

3.2.1.2. Backlash-free transmission . . . . . . . . . . 43

3.2.1.3. Constant input angular velocity. . . . . . . . 43 
3.2.2. Lumped mass . . . . . . . . . . . . . . . . . . . 43

3.2.3. Decay of residual vibration . . . . . . . . . . . . . 43

3.2.4. No damping during cam rise . . . . . . . . . . . . . 44

3.3. Dynamic response . . . . . . . . . . . . . . . . . . . . 44

3.4. Damping . . . . . . . . . . . . . . . . . . . . . . . . 47

3.5. Maximum and zero points . . . . . . . . . . . . . . . . . 48

3.6. Backlash ... . . . . . . . . . . . . . . . . . . . . . 48

3.7. Many degrees of freedom . . . . . . . . . . . . . . . . . . 50

3.7.1. Transfer function . . . . . . . . . . . . . . . . . 50

3.7.2. Natural frequencies . . . . . . . . . . . . . . . . . . 52

3.7.3. Response . . . . . . . . . . . . . . . . . . . . 52

3.8. Conclusions . . . . . . . . . . . . . . . . . . . . . . 56

4. SINGLE-DEGREE-OF-FREEDOM MODEL WITH VARIABLE FICTITIOUS ANGULAR VELOCITY, "CAMSHAFT-1" . . . 58

4.1. Introduction . . . . . . . . . . . . . . . . . . . . . . . 58

4.2. Assumptions .

4.2.1. Constant input angular velocity . . . . . . . . . . . . 59

4.2.2. Constant mass . . . . . . . . . . . . . . . . . . . . . . . 59

4.2.3. Variable stiffness . . . . . . . . . . . . . . . . . . . 60

4.2.4. No damping during cam rise . . . . . . . . . . . . . . . 60

4.2.5. Constant pitch radius . . . . . . . . . . . . . . . . 61

4.3. Description of the model . . . . . . . . . . . . . . . . . 62

4.3.1. Equations . . . . . . . . . . . . . . . . . . . . . 62

4.3.2. Dimensionless numbers . . . . . . . . . . . . . . . . . 64

4.3.2.1. Introduction . . . . . . . . . . . . . . . . . . . . . 64

4.3.2.2. Definitions . . . . . . . . . . . . . . . . . 64

4.3.2.3. Dimensionless parameters . . . . . . . . . . 65

4.3.2.4. Dimensionless equations . . . . . . . . . . . . 65

4.4. Methods of solution . . . . . . . . . . . . . . . . . . . 66

4.4.1. Approximative method . . . . . . . . . . . . . . . 66

4.4.2. Numerical method . . . . . . . . . . . . . . . . . 68

4.5. Results of the CAMSHAFT-1 program . . . . . . . . . . . 70

4.5.1. Acceleration phase . . . . . . . . . . . . . . . . . 70

4.5.2. Deceleration phase . . . . . . . . . . . . . . . . . 71

4.5.3. Natural frequency . . . . . . . . . . . . . . . . . 71

4.5.4. Residual vibration . . . . . . . . . . . . . . . . 73

4.5.5. Response graphs . . . . . . . . . . . . . . . . . . . 74

4.6. Simple method for calculating the lowest natural frequency . . 74

4.7. Conclusions . . . . . . . . . . . . . . . . . . . . . 77 
5. TWO-DEGREES-OF-FREEDOM MODEL, "CAMSHAFT-2" . . 79

5.1. Introduction . . . . . . . . . . . . . . . . . 79

5.2. Assumptions . . . . . . . . . . . . . . . . . . . . . . . . . . . . . . 79

5.2.1. Two degrees of freedom . . . . . . . . . . . . . . 79

5.2.2. Constant input angular velocity . . . . . . . . . . . 81

5.3. Description of the model . . . . . . . . . . . . . . . . . 81

5.3.1. Equations . . . . . . . . . . . . . . . . . 81

5.3.2. Dimensionless numbers . . . . . . . . . . . . . . . 82

5.3.2.1. Definitions . . . . . . . . . . . . . . . . . 82

5.3.2.2. Dimensionless parameters . . . . . . . . . . 83

5.3.2.3. Dimensionless equations . . . . . . . . . . . 83

5.4. Method of solution . . . . . . . . . . . . . . . . . . . . 84

5.5. Results of the CAMSHAFT-2 program . . . . . . . . . . . 88

5.5.1. Shaft flexibility . . . . . . . . . . . . . . . . . . 88

5.5.2. Acceleration phase of the cam rise . . . . . . . . . . 88

5.5.3. Deceleration phase of the cam rise . . . . . . . . . . 88

5.5.4. Residual vibration . . . . . . . . . . . . . . . . 88

5.5.5. Dynamic behaviour of the shaft . . . . . . . . . . . 88

5.5.6. Response graphs . . . . . . . . . . . . . . . . . . 90

5.5.7. Natural frequencies . . . . . . . . . . . . . . . . 90

5.5.7.1. Highest natural frequency . . . . . . . . . . 93

5.5.7.2. Lowest natural frequency . . . . . . . . . . 94

5.6. Extension to more degrees of freedom . . . . . . . . . . . . . 94

5.7. Conclusions . . . . . . . . . . . . . . . . . . . . . . . 98

6. FOUR-DEGREES-OF-FREEDOM MODEL, "DYNACAM" . . 100

6.1. Introduction . . . . . . . . . . . . . . . . . . 100

6.2. Assumptions . . . . . . . . . . . . . . . . . . . . . . . 100

6.2.1. Four degrees of freedom . . . . . . . . . . . . . 100

6.2.2. Damping . . . . . . . . . . . . . . . . . . . . . 100

6.2.3. Backlash and squeeze. . . . . . . . . . . . . . . . 100

6.2.4. Follower jumping . . . . . . . . . . . . . . . . . 100

6.2.5. Nonconstant angular velocity of the driving machine . . 101

6.3. Numerical calculations . . . . . . . . . . . . . . . . . . 102

6.4. The purpose of the DYNACAM model . . . . . . . . . . . 102

6.5. Equations of the cam mechanism . . . . . . . . . . . . . . 102

6.5.1. Input motion . . . . . . . . . . . . . . . . . . . 102

6.5.2. Backlash in reduction gear . . . . . . . . . . . . 102

6.5.3. Torsion of the camshaft . . . . . . . . . . . . . 105

6.5.4. Deflection of the camshaft parallel to the direction of motion of the follower roller . . . . . . . . . . . . 106 
6.5.5. Deflection of the camshaft perpendicular to the direction of motion of the follower roller . . . . . . . . . . . 106

6.5.6. Frictional forces acting on the rotating system . . . . . 106

6.5.7. Rotation of the cam . . . . . . . . . . . . . . . . 107

6.5.8. Displacement of the cam parallel to the direction of motion of the follower roller . . . . . . . . . . . . . 107

6.5.9. Displacement of the cam perpendicular to the direction of motion of the follower roller . . . . . . . . . . . 107

6.5.10. Cam curve . . . . . . . . . . . . . . . . . . . . 107

6.5.11. Instantaneous slope of the cam curve, instantaneous pitch radius, instantaneous roller displacement, and instantaneous roller velocity . . . . . . . . . . . . . . . . . . . . 107

6.5.12. Backlash of the roller in its groove . . . . . . . . . . 109

6.5.13. Deformation of the follower linkage . . . . . . . . . 111

6.5.14. External friction of the follower linkage . . . . . . . . 112

6.5.15. Motion of the follower output member . . . . . . . . 113

6.5.16. Follower spring . . . . . . . . . . . . . . . . . . 113

6.5.17. External forces . . . . . . . . . . . . . . . . . . 113

6.5.18. Damping . . . . . . . . . . . . . . . . . . 113

6.5.19. Integrals . . . . . . . . . . . . . . . 113

6.5.20. Initial conditions . . . . . . . . . . . . . . . . . . 114

6.6. Block diagram . . . . . . . . . . . . . . . . . . . . 117

6.7. Equations of the asynchronous motor and the reduction gear 117

7. ANALYSIS OF MACHINE DYNAMICS . . . . . . . . 120

7.1. Introduction . . . . . . . . . . . . . . . . . . . . . 120

7.2. Particulars of the test mechanism . . . . . . . . . . . . . . 120

7.3. Measuring equipment . . . . . . . . . . . . . . . . . . . 124

7.4. Follower-response measurements explained by means of simulation . . . . . . . . . . . . . . . . . 125

7.4.1. Static characteristics . . . . . . . . . . . . 125

7.4.1.1. Backlash . . . . . . . . . . . . . . . 125

7.4.1.2. Stiffness . . . . . . . . . . . . . . . . 125

7.4.1.3. Hysteresis . . . . . . . . . . . . . . . . . 128

7.4.2. Measured dynamic characteristics . . . . . . . . . . 131

7.4.3. Simulation with the DYNACAM program . . . . . . 131

7.4.4. Traversing of backlash . . . . . . . . . . . . . 132

7.4.5. Damping ..... . . . . . . . . . . . . . 143

7.4.6. Squeeze. . . . . . . . . . . . . . . . . . . . . 147

7.4.7. Conclusions . . . . . . . . . . . . . . . . . . . . 147

7.5. Follower jumping . . . . . . . . . . . . . . . . . . . . . 147

7.6. Flexible shaft . . . . . . . . . . . . . . . . . . . . . . 147 
8. COMPARISON OF THE RESPONSES OF THE VARIOUS DYNAMIC MODELS WITH THOSE OF REAL MECHANISMS, AND RULES OF DESIGN . . . . . . . . . . . . . . . . . 151

8.1. Introduction . . . . . . . . . . . . . . . . . . . 151

8.2. Comparison of the responses of the various dynamic models of cam mechanisms with those of real mechanisms . . . . . . . 151

8.2.1. Four-degrees-of-freedom model . . . . . . . . . . . 151

8.2.2. Damping . . . . . . . . . . . . . . . . . . . . 156

8.2.3. Follower spring . . . . . . . . . . . . . . . . . . 156

8.2.4. Two-degrees-of-freedom model . . . . . . . . . . . 156

8.2.5. Single-degree-of-freedom model with variable fictitious angular velocity . . . . . . . . . . . . . . . . . 157

8.2.6. The envelope curve $U_{0}\left(\tau, F_{a}\right)$. . . . . . . . . . . . . . . 157

8.2.7. Constant pitch radius . . . . . . . . . . . . . . . . . . 157

8.2.8. Conclusions . . . . . . . . . . . . . . . . . . . . 161

8.3. Selection of the asynchronous motor . . . . . . . . . . . 162

8.4. Alternative cam curves . . . . . . . . . . . . . . . . . . 163

8.5. Rules of design . . . . . . . . . . . . . . . . . . . . . 168

8.6. Conclusions . . . . . . . . . . . . . . . . . . 171

9. CONCLUSIONS AND RECOMMENDED FURTHER INVESTIGATIONS . . . . . . . . . . . . . . . . . 172

9.1. Conclusions . . . . . . . . . . . . . . . . . . . 172

9.2. Recommended further investigations . . . . . . . . . . . . 172

9.2.1. Roller vibration . . . . . . . . . . . . . . . . . . 172

9.2.2. Basic cam curve . . . . . . . . . . . . . . . . . . 173

9.2.3. Damping . . . . . . . . . . . . . . . . . . . . 173

9.2.4. Dynamic behaviour of the frame . . . . . . . . . . . 174

9.2.5. Considerations of practical design . . . . . . . . . . 174

9.2.6. Dynamic behaviour of multibar linkages . . . . . . . 174

APPENDIX 1. Dynamic models of machine components . . . . . . . 175

APPENDIX 2. Nominal characteristics of the cycloidal and the modified sine cam curve . . . . . . . . . . . . . . . . . . 179

A.2.1. Introduction . . . . . . . . . . . . . . . . . . . . . . 179

A.2.2. General . . . . . . . . . . . . . . . . . . . . . . . 179

A.2.3. Cycloidal cam curve . . . . . . . . . . . . . . . . . . 180

A.2.4. Modified sine cam curve. . . . . . . . . . . . . . . 182 
APPENDIX 3. Rayleigh's method for the calculation of the lowest natural frequency . . . . . . . . . . . . . . . . 184

A.3.1. Introduction . . . . . . . . . . . . . . . . . . . . . . 184

A.3.2. Rayleigh's method . . . . . . . . . . . . . . . . . . . 184

A.3.3. Exact method for lumped masses . . . . . . . . . . . . . . 184

A.3.4. Approximative single-degree-of-freedom system . . . . . . . 185

A.3.5. The accuracy of Rayleigh's method in the two-degrees-of-freedom system . . . . . . . . . . . . . . . . . . . . . . 185

A.3.6. Measure of the accuracy of Rayleigh's method . . . . . . . 186

A.3.6.1. Multi-degree-of-freedom systems . . . . . . . . . 186

A.3.6.2. Intermediate masses exceed the output member mass 188

A.3.6.3. Directive for calculation of the lowest natural frequency . . . . . . . . . . . . . . . . 191

APPENDIX 4. Squeeze . . . . . . . . . . . . . . . . . . . . . 192

A.4.1. Two-dimensional, steady-state viscous flow . . . . . . . . . 192

A.4.2. Squeeze . . . . . . . . . . . . . . . . . . . . . . . 193

APPENDIX 5. Asynchronous motor . . . . . . . . . . . . . . . 195

A.5.1. Introduction . . . . . . . . . . . . . . . . . . . . . . 195

A.5.2. Electromagnetic torque . . . . . . . . . . . . . . . . 195

A.5.3. Equations of the motor . . . . . . . . . . . . . . . . 197

A.5.4. Methods of solution . . . . . . . . . . . . . . . . . . 198

A.5.4.1. Motor considered as a second-order system . . . . 198

A.5.4.1.1. Numerical solution . . . . . . . . . . . 198

A.5.4.1.2. Analytical solution . . . . . . . . . . 198

A.5.4.2. Motor considered as a first-order system . . . . . . 203

A.5.4.3. Comparison of the actual response characteristics of the asynchronous motor with those of the various dynamic models . . . . . . . . . . . . 205

A.5.4.3.1. Second-order dynamic model . . . . . . 205

A.5.4.3.2. Efficiency of the reduction gear . . . . . 207

A.5.4.3.3. Spring load . . . . . . . . . . . . . . 207

A.5.4.3.4. Damping . . . . . . . . . . . . . . 207

A.5.4.3.5. Analytical calculation, second-order system 208

A.5.4.3.6. Analytical calculation, first-order system . 209

A.5.4.3.7. Motor-speed variations affecting the cam follower response . . . . . . . . . . . 209

A.5.4.3.8. Conclusions . . . . . . . . . . . . . 210

APPENDIX 6. Program "DYNACAM" . . . . . . . . . . . . . 211 
APPENDIX 7. Calculations of dynamic models . . . . . . . . . 215

A.7.1. Introduction . . . . . . . . . . . . . . 215

A.7.2. Indexing mechanism . . . . . . . . . . . . . . . . 215

A.7.3. Cam follower mechanism . . . . . . . . . . . . . . . 218

A.7.3.1. Four-degrees-of-freedom model . . . . . . . . . 218

A.7.3.2. Two-degrees-of-freedom model . . . . . . . . . . 221

REFERENCES . . . . . . . . . . . . . . . . . . . . 223 


\section{SYMBOLS}

Indices of symbols occurring frequently are listed separately at the end of this nomenclature. Numbers between parentheses refer to equations in which the symbols have been used or defined.

$x \quad$ angle of pressure exerted by the cam (2.52)

$x_{\mathrm{mc}} \quad\left(=\arctan \left(h_{m} / R_{1 / 2} \beta_{m}\right)\right)$ mean angle of pressure exerted by the cam (4.13)

$x_{1} \quad$ angle of pressure exerted by gear teeth (6.71)

$\beta \quad$ angular position of the cam

$\beta_{m} \quad$ angle of the cam curve

$\gamma \quad$ density

$\left(\mathrm{kg} / \mathrm{m}^{3}\right)$

.1.. difference: (1) increment (4.28);

(2) deviation

$\delta$

$\delta \ldots \quad$ increment (4.23) slip of the asynchronous motor (8.1)

$\delta_{k}$ critical slip (A.5.3)

$\delta_{1 \mathrm{~m}} \quad$ maximum allowable slip (8.1)

$\varepsilon \quad$ contact ratio (6.3)

$\eta_{\rho} \quad$ efficiency of reduction gear (A.5.34)

$\eta \quad$ dynamic viscosity of lubricant (A.4.2)

$\theta \quad$ (1) $(=.1 T / 2)$ half the time step $\Delta T(4.24),(5.21)$;

(2) instant of occurrence of maximum nominal acceleration of the modified sine cam curve (A.2.17)

$\lambda$ eigenvalue (2.50)

angle of friction (6.71)

$(\mathrm{rad})$

coefficient of friction (6.13)

constant (4.22)

radius of curvature of the cam (6.31)

$\left(\mathrm{Ns} / \mathrm{m}^{2}\right)$

$\boldsymbol{v}$

$\zeta$

Q

Opitch

radius of curvature of the pitch curve (6.30)

(m)

pressure in fluid (A.4.1)

(m)

$\sigma_{\boldsymbol{p}}$

shear stress in fluid (A.4.2)

$\left(\mathrm{N} / \mathrm{m}^{2}\right)$

$\sigma_{s}$

$\tau \quad T_{c} / t_{m}(3.3)$

$\left(\mathrm{N} / \mathrm{m}^{2}\right)$

$\tau_{\mathrm{cl}} \quad T_{\mathrm{cl}} / t_{m}$ (A.5.23)

$\tau_{m} \quad T_{m} / t_{m}$ (A.5.24)

$\phi_{v} \quad$ volume flow (A.4.4)

$\phi \quad\left(=\varphi / \beta_{m}\right)$ dimensionless angular position of the driving machine

$\varphi \quad$ angular position of the driving machine, reduced at camshaft 


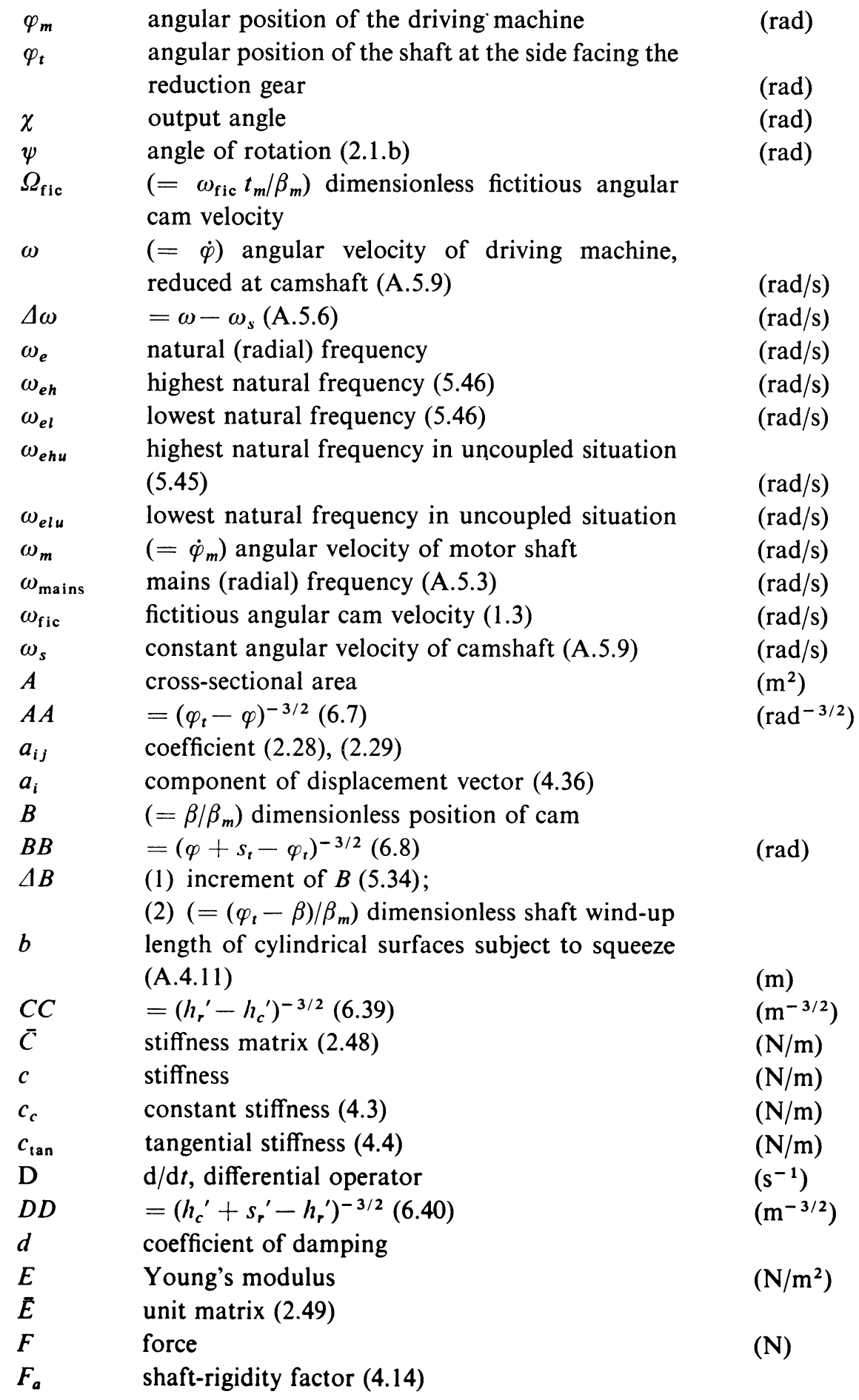




\begin{tabular}{|c|c|c|}
\hline$F_{b}$ & impact force & $(\mathrm{N})$ \\
\hline$F_{\text {ex }}$ & external force & $(\mathrm{N})$ \\
\hline$F_{v}$ & flywheel factor (5.14) & \\
\hline$F_{0}$ & follower-spring preload & $(\mathrm{N})$ \\
\hline$f$ & displacement of foundation & (m) \\
\hline$G$ & (1) modulus of shear; & $\left(\mathrm{N} / \mathrm{m}^{2}\right)$ \\
\hline & (2) linearised static characteristic (A.5.1) & $(\mathrm{Nm} \mathrm{s} / \mathrm{rad})$ \\
\hline$G_{0}$ & $\begin{array}{l}\text { slope of tangent to static characteristic at zero } \\
\text { torque (A.5.4.a) }\end{array}$ & $(\mathrm{Nm} \mathrm{s} / \mathrm{rad})$ \\
\hline$H$ & $\left(=h^{\prime} / h_{m}{ }^{\prime}\right)$ dimensionless cam-curve displacement & \\
\hline$h$ & cam-curve displacement (A.3.2) & (m) \\
\hline $\bar{h}$ & input displacement vector (2.48) & (m) \\
\hline$h_{c}$ & $\begin{array}{l}\text { displacement of the centre of a backlash-free fol- } \\
\text { lower roller }(2.52)\end{array}$ & (m) \\
\hline$h_{m}$ & stroke at cam & (m) \\
\hline$h_{r}$ & position of the centre of the roller & (m) \\
\hline$I$ & moment of inertia of a cross-section & $\left(\mathrm{m}^{4}\right)$ \\
\hline$I_{p}$ & polar moment of inertia of a cross-section & $\left(\mathrm{m}^{4}\right)$ \\
\hline$i$ & transmission ratio & \\
\hline$i_{t}$ & transmission ratio of reduction gear (A.5.6) & \\
\hline$i_{x}$ & transmission ratio of the follower linkage & \\
\hline$J$ & polar mass moment of inertia of the cam & $\left(\mathrm{kg} \mathrm{m}^{2}\right)$ \\
\hline$J_{m}$ & $\begin{array}{l}\text { polar mass moment of inertia of the driving } \\
\text { machine (A.5.7) }\end{array}$ & $\left(\mathrm{kg} \mathrm{m}^{2}\right)$ \\
\hline $\bar{K}$ & stiffness matrix $(2.48)$ & $(\mathrm{N} / \mathrm{m})$ \\
\hline$k$ & $\left(=G I_{p} / I I\right)$ torsional stiffness & $(\mathrm{Nm} / \mathrm{rad})$ \\
\hline$l$ & length of bar, beam, or shaft & (m) \\
\hline$M$ & torque in camshaft (A.2.5) & $(\mathrm{Nm})$ \\
\hline $\bar{M}$ & mass matrix $(2.48)$ & $(\mathrm{kg})$ \\
\hline$M_{e}$ & electromagnetic torque of driving machine (A.5.1) & $(\mathrm{Nm})$ \\
\hline$M_{k}$ & critical torque of the electric motor (A.5.4.a) & $(\mathrm{Nm})$ \\
\hline$M_{m}$ & external torque on the driving machine (A.5.7) & $(\mathrm{Nm})$ \\
\hline$m$ & mass & $(\mathrm{kg})$ \\
\hline$m_{t}$ & modulus of output gear wheel $(6.15)$ & (m) \\
\hline$m_{\text {tan }}$ & mass in tangential direction (5.51) & $(\mathrm{kg})$ \\
\hline$N$ & power $(8.3)$ & $(W)$ \\
\hline$n$ & integer & \\
\hline$P$ & $\left(=M_{\text {ena }} / M_{\max }\right)$ ratio of overdimensioning (A.5.15) & \\
\hline$P_{\beta}$ & $\left(=M /\left(\beta_{m} c_{\beta}^{\prime} R_{b}^{\prime 2}\right)\right)$ dimensionless torque & \\
\hline$p$ & number of pairs of poles (A.5.4.a) & \\
\hline$Q$ & force in a nodal point $(2.28),(2.29)$ & $(\mathrm{N})$ \\
\hline$Q^{*}$ & generalised force $(2.27)$ & $(\mathrm{N})$ \\
\hline
\end{tabular}




\begin{tabular}{|c|c|c|}
\hline$q$ & relative damping $(1.2)$ & \\
\hline$R(\beta)$ & instantaneous pitch radius of cam curve $(2.53)$ & $(\mathrm{m})$ \\
\hline$R_{B}$ & $\begin{array}{l}\left(=R^{\prime}(\beta) / h_{m}{ }^{\prime}\right) \text { dimensionless instantaneous pitch } \\
\text { radius }\end{array}$ & \\
\hline$R_{e}$ & effective radius of curvature (A.4.8) & $(\mathrm{m})$ \\
\hline$R_{b}$ & base pitch radius $(4.1)$ & (m) \\
\hline$R_{1 / 2}$ & $\left(=R_{b}+\frac{1}{2} h_{m}\right)$, mean pitch radius $(4.1)$ & (m) \\
\hline$R_{r}$ & radius of roller $(6.31)$ & (m) \\
\hline$r_{c}$ & $\left(=v_{b} t_{m} / h_{m}{ }^{\prime}\right)$ dimensionless impact velocity (3.16) & \\
\hline$S_{r}$ & $\begin{array}{l}\left(=s_{r}{ }^{\prime} / h_{m}{ }^{\prime}\right) \text { dimensionless backlash of the roller } \\
\text { in the cam groove }\end{array}$ & \\
\hline$S_{t}$ & $\left(=s_{t} / \beta_{m}\right)$ dimensionless backlash in reduction gear & \\
\hline$S_{f}$ & instantaneous minimum film thickness (A.4.10) & $(\mathrm{m})$ \\
\hline$s$ & backlash (3.16) & $(\mathrm{m})$ \\
\hline$s_{f}$ & instantaneous film thickness (A.4.3) & $(\mathrm{m})$ \\
\hline$s_{\beta 0}$ & initial position of shaft $(6.61)$ & (rad) \\
\hline$s_{x 0}$ & initial position of roller $(6.56 . b)$ & $(\mathrm{m})$ \\
\hline$T$ & $\begin{array}{l}\text { (1) }\left(=t / t_{m}\right) \text { dimensionless time (A.2.1); } \\
\text { (2) kinetic energy (2.7) }\end{array}$ & $(\mathrm{Nm})$ \\
\hline$T_{e}$ & period of natural vibration $(3.3)$ & (s) \\
\hline$T_{\mathrm{e} 1}$ & electrical time constant (A.5.3) & (s) \\
\hline$T_{m}$ & mechanical time constant (A.5.11) & (s) \\
\hline$t$ & time & (s) \\
\hline$t_{c}$ & time of a shaft cycle & (s) \\
\hline$t_{d}$ & dwell time & (s) \\
\hline$t_{m}$ & cam rise time $(3.2)$ & (s) \\
\hline$U_{s n}$ & $\begin{array}{l}\left(=U_{s n} / h_{m}{ }^{\prime}\right) \text { dimensionless impact amplitude } \\
(3.11)\end{array}$ & \\
\hline$U_{s n}$ & $\begin{array}{l}\left(=\ddot{u}_{s n} t_{m}{ }^{2} / h_{m}{ }^{\prime}\right) \text { dimensionless amplitude of the } \\
\text { acceleration at impact }(3.12)\end{array}$ & \\
\hline$U_{0}$ & $\left(=U_{0} / h_{m}{ }^{\prime}\right)$ dimensionless positional error (3.5) & \\
\hline$U_{0}$ & $\begin{array}{l}\left(=\ddot{u}_{0} t_{m}{ }^{2} / h_{m}{ }^{\prime}\right) \text { dimensionless amplitude of the } \\
\text { residual acceleration (3.6) }\end{array}$ & \\
\hline$u$ & $\left(=x-h_{m}{ }^{\prime}\right)$ instantaneous positional error (3.4) & (m) \\
\hline$u_{s n}$ & impact amplitude (3.11) & $(\mathrm{m})$ \\
\hline$\ddot{u}_{s n}$ & amplitude of the acceleration at impact (3.12) & $\left(\mathrm{m} / \mathrm{s}^{2}\right)$ \\
\hline$u_{0}$ & amplitude of the positional error (3.5) & $(\mathrm{m})$ \\
\hline$\ddot{u}_{0}$ & amplitude of the residual acceleration (3.6) & $\left(\mathrm{m} / \mathrm{s}^{2}\right)$ \\
\hline$V$ & potential energy $(2.5)$ & $(\mathrm{Nm})$ \\
\hline$v$ & $\begin{array}{l}\text { velocity in fluid film parallel to squeezing surfaces } \\
\text { (A.4.3) }\end{array}$ & \\
\hline
\end{tabular}


$\boldsymbol{v}_{\boldsymbol{b}}$

$V R$

$V T$

$w$

X

$x$

$x_{d}$

$x_{e}$

$x_{s}$

$x$

$z_{t}$

\section{Indices}

$\beta$

$a$

$e$

eq

$f$

$l$

$\max$

me

$\min$

$n$

$r$

ri

$s$ impact speed (3.13)

squeeze term related to squeeze between the roller and the groove wall (6.38)

$(\mathrm{m} / \mathrm{s})$

$\left(\mathrm{Ns} \mathrm{m}^{3 / 2}\right)$

squeeze term related to squeeze in the reduction gear (6.6)

squeeze velocity (A.4.5)

$\left(\mathrm{Ns} \mathrm{m}^{3 / 2}\right)$

$(\mathrm{m} / \mathrm{s})$

$\left(=x / h_{m}\right)$ dimensionless position of the output member

position of output member (1.2)

(m)

dynamic displacement function

elastic displacement function (2.2)

(m)

displacement function with dynamic coupling

neglected

(m)

displacement vector (2.48) (m)

number of teeth of the output gear wheel (6.15) 